\section{International Scientific Journal Theoretical \& Applied Science}

\author{
p-ISSN: 2308-4944 (print) e-ISSN: 2409-0085 (online) \\ Year: 2016 Issue: 11 Volume: 43 \\ Published: 17.11.2016 http://T-Science.org
}

SECTION 7. Mechanics and machine construction.
Denis Chemezov

Master of Engineering and Technology, Corresponding

Member of International Academy of Theoretical and Applied Sciences, Lecturer of Vladimir Industrial College, Russian Federation chemezov-da@yandex.ru

Timur Osipov Student of Vladimir Industrial College, Russian Federation $\underline{\text { fmotd23@mail.ru }}$

Andrey Pesenko Student of Vladimir Industrial College, Russian Federation

\title{
A STATIC CALCULATION OF AN I-BEAM
}

Abstract: The article is presented a qualitative assessment of the stress-strain state of an I-beam, rigidly clamped at the one end in a wall, under the action of the constant distributed load.

Key words: an I-beam, stress, deformation, a model.

Language: Russian

Citation: Chemezov D, Osipov T, Pesenko A (2016) A STATIC CALCULATION OF AN I-BEAM. ISJ Theoretical \& Applied Science, 11 (43): 49-52.

Soi: http://s-o-i.org/1.1/TAS-11-43-10 Doi: crossef http://dx.doi.org/10.15863/TAS.2016.11.43.10

\section{СТАТИЧЕСКИЙ РАСЧЕТ ДВУТАВРОВОЙ БАЛКИ}

Аннотация: В статье представлена качественная оценка напряженно-деформированного состояния двутавровой балки, жестко заделанной одним кониом в стену, под действием постоянной распределенной нагрузки.

Ключевые слова: двутавровая балка, напряжение, деформащчия, модель.

\section{Введение}

Двутавровая балка имеет стандартный профиль, имеющий сечение близкое по форме к букве «Н» [1]. Двутавры изготавливаются из черного проката или дерева. Преимуществом двутавровой балки, по сравнению с балками круглого или квадратного профилей с аналогичной площадью сечения, является большая жесткость и прочность при воздействии поперечных нагрузок. Недостатком при эксплуатации двутавровой балки является малая устойчивость к скручиванию.

Расчет двутавровых балок производят на прогиб (по деформациям) и изгиб (по несущей способности) [2]. Расчет может выполняться по нескольким схемам нагружения двутавров: однопролетная балка с приложенной на нее равномерно распределенной нагрузкой, которая шарнирно оперта (1); консоль с жесткой заделкой на одном из концов, на которую приложена равномерно распределенная нагрузка (2); однопролетная балка с консолью с одной стороны, на которую также приложена равномерно распределенная нагрузка (3); однопролетная шарнирно опертая балка с приложенной на нее сосредоточенной силой (4); однопролетная шарнирно опертая балка с приложенной на нее двух сосредоточенных сил (5); консоль с жесткой заделкой, на которую приложена сосредоточенная сила (6). Формулы для расчета и выбор размеров сечения двутавровой балки приводятся в работе [3].

Определение по аналитическим формулам напряженного состояния материала двутавровой балки под действием нагрузок - трудоемкий процесс. Применяя компьютерные программы инженерного анализа можно получить качественную оценку напряженного и деформированного состояния материала при воздействии на фланец двутавровой балки распределенных сил.

\section{Материалы и методы исследования}

Для реализации компьютерного расчета напряженного и деформированного состояния двутавровой балки в программе SolidWorks Premium 2012 были заданы следующие начальные условия:

1. 3D модель двутавровой балки №10 [4] общей длиной 600 мм. 
2. Материал модели двутавровой балки углеродистая сталь обыкновенного качества марки Ст3 [5]. Для данной стали выбираются следующие физико-механические свойства: предел текучести - $2.20594 \cdot 10^{8} \mathrm{H} / \mathrm{M}^{2}$, предел прочности при растяжении - $3.99826 \cdot 10^{8} \mathrm{H} / \mathrm{M}^{2}$, коэффициент Пуассона -0.28 , модуль упругости - $2.1 \cdot 10^{11} \mathrm{H} / \mathrm{M}^{2}$, модуль сдвига $7.9 \cdot 10^{10} \mathrm{H} / \mathrm{m}^{2}$, коэффициент теплового расширения $1.3 \cdot 10^{-5} \mathrm{~K}^{-1}$, массовая плотность $-7800 \mathrm{\kappa г} / \mathrm{M}^{3}$.

Масса двутавровой балки составила 5.7 кг, объем - $0.000730721 \mathrm{~m}^{3}$.

3. Тип проводимого анализа - статический, с включением тепловых нагрузок. Температура при нулевом напряжении материала балки принималась величиной 298 К. Расчет осуществлялся решающей программой FFEPlus [6].

4. Крепление модели осуществлялось за поверхность контура (в поперечном сечении) на левой стороне двутавровой балки (схема 2). Балка была нагружена распределенными силами величиной 2.5 кН.

5. Высокое качество разбиения модели двутавровой балки на конечные элементы позволило получить стандартную сетку из 95328 узлов (56423 элемента) [7]. Для проверки уровня искажения тетраэдральных элементов установлены 4 точки интегрирования (точки Якобиана). Размер конечного элемента модели составил 4.8907 мм при допуске от глобального размера элемента равном 0.244537 мм.

Лучшая точность достигается на сетке с одинаковыми идеальными элементами, чьи кромки равны по длине. Из-за малых кромок, изогнутой формы, тонкостенных элементов и острых углов одни кромки некоторых созданных элементов длиннее других. Соотношение сторон (пропорции) конечных элементов модели составляет от 1.02106 (синий цвет на эпюре точность результатов повышается) до 6.71787 (красный цвет на эпюре - точность результатов снижается).

Квадратичные элементы могут отображать изогнутую геометрию намного более точно, чем линейные элементы такого же размера. На очень острых или изогнутых границах размещение средних узлов может привести к образованию искаженных конечных элементов с пересекающимися кромками. Коэффициент Якобиана составляет от 1 до 2.38383 .

Этапы подготовки к расчету напряженнодеформированного состояния двутавровой балки представлены на рис. 1.

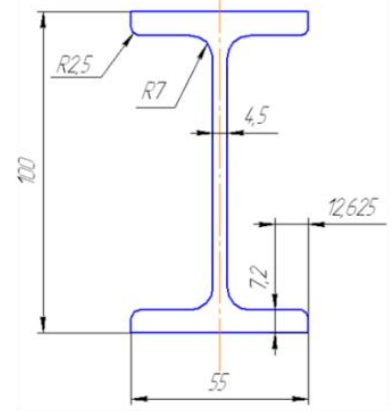

a)

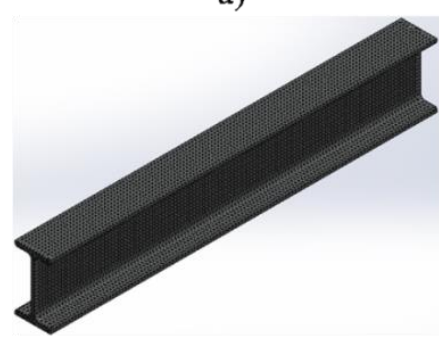

г)

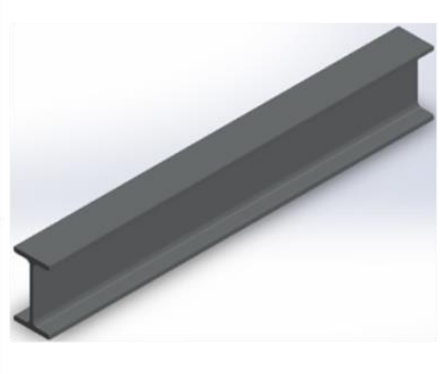

б)

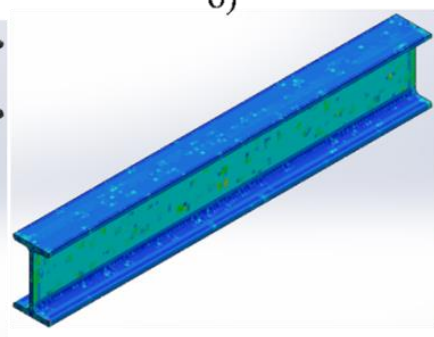

д)

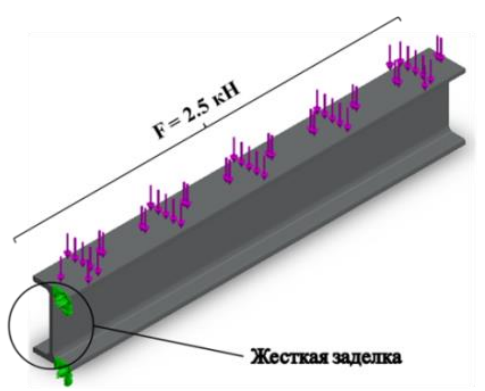

B)

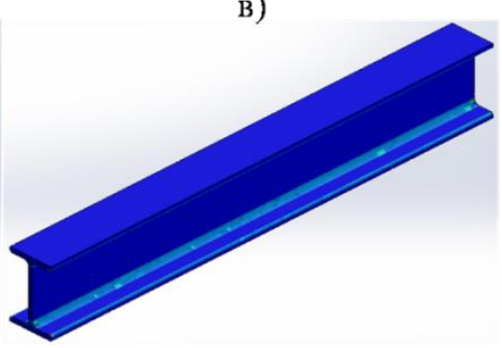

e)

Рисунок 1 - Этапы подготовки к расчету напряженно-деформированного состояния двутавровой балки №10: а - эскиз двутавровой балки; б - твердотельная объемная модель двутавровой балки; в схема нагружения модели двутавровой балки; г - разбиение модели двутавровой балки на конечные элементы; д - эпюра качества сетки (пропорции); е - эпюра качества сетки (коэффициент распределения элементов Якобиана).

Результаты и их обсуждение

Для статического анализа предусмотрено визуальное отображение результатов расчета в виде эпюр напряжения по фон Мизесу, результирующего перемещения, эквивалентной деформации, наиболее нагруженных участков и распределения запаса прочности по критерию

ISPC Education and Innovation, 
максимального напряжения (по фон Мизесу) [8] материала двутавровой балки.

Результаты компьютерного расчета напряженного и деформированного состояния материала двутавровой балки представлены на рис. 2.

Наибольшее напряжение материала балки концентрируется в области заделки. Двумя сечениями двутавровой балки дается характер

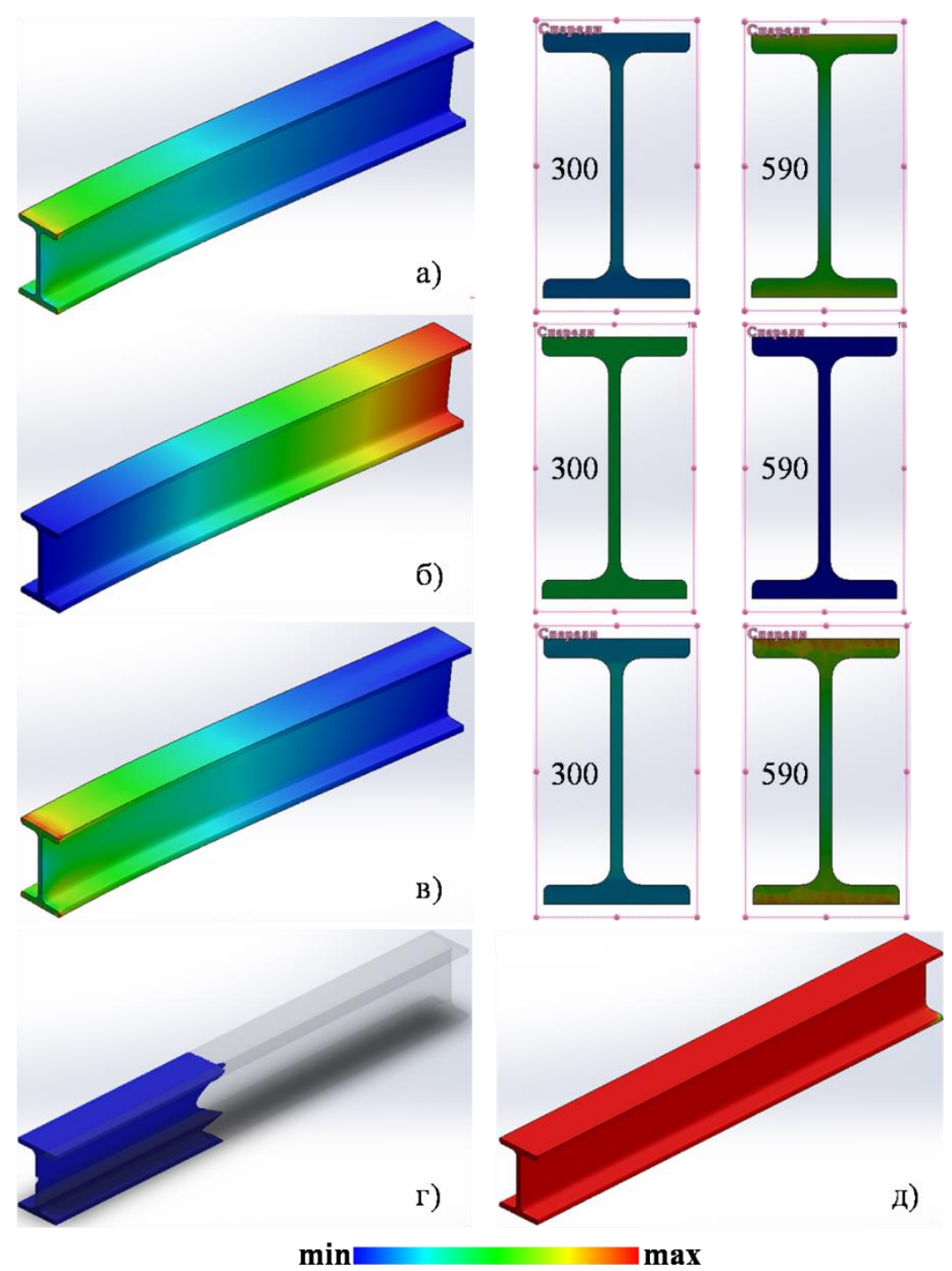

Рисунок 2 - Результаты компьютерного расчета: а - эпюра напряжения по фон Мизесу и сечения двутавровой балки на указанной длине; б - эпюра результирующего перемещения и сечения

двутавровой балки на указанной длине; в - эпюра эквивалентной деформации и сечения двутавровой балки на указанной длине; г - эпюра наиболее нагруженных участков двутавровой балки (Design Insight); д - эпюра распределения запаса прочности по критерию максимального напряжения (по фон Мизесу).

Отклонение двутавровой балки от нормали составляет 0.12 мм на консольной части. Результирующее перемещение происходит на 2/3 длины двутавровой балки.

Распределение эквивалентной деформации материала двутавра аналогично напряжению по фон Мизесу. Стенка двутавра деформируется напряженного состояния внутренних слоев материала. За 0 мм принят свободный от закрепления конец двутавровой балки, за 600 мм - жестко заделанный конец. Рассчитанные величины напряжения двутавровой балки (max $2.87887 \cdot 10^{7} \mathrm{H} / \mathrm{M}^{2}$ ) не приводят к текучести материала. На длине двутавровой балки до 300 мм статическое напряжение по фон Мизесу материала практически отсутствует.

д)

ISPC Education and Innovation,

меньше, чем фланцы. Наибольшая величина эквивалентной деформации материала балки составила $9.47032 \cdot 10^{-5}$.

Эпюра Design Insight показывает области модели, которые несут нагрузки наиболее эффективно. Более нагруженные области балки 


\begin{tabular}{l|lrl|l|ll} 
& ISRA (India) & $=\mathbf{1 . 3 4 4}$ & SIS (USA) & $=\mathbf{0 . 9 1 2}$ & ICV (Poland) & $=\mathbf{6 . 6 3 0}$ \\
Impact Factor: & ISI (Dubai, UAE) $=\mathbf{0 . 8 2 9}$ & PUHL (Russia) $=\mathbf{0 . 2 3 4}$ & PIF (India) & $=\mathbf{1 . 9 4 0}$ \\
& GIF (Australia) & $\mathbf{0 . 5 6 4}$ & ESJI (KZ) & $=\mathbf{1 . 0 4 2}$ & IBI (India) & $=\mathbf{4 . 2 6 0}$
\end{tabular}

обозначаются синим цветом. При заданной нагрузке этот объем составляет $41.12 \%$.

Коэффициент запаса прочности для балки принимается величиной 7.66. Эта величина соответствует несущим элементам конструкций долговременного использования.

\section{Заключение}

Статический анализ не дает полной оценки напряженного и деформированного состояния двутавровой балки. Путем загрузки результатов исследования в другие расчетные модули программы SolidWorks («Частота», «Потеря устойчивости», «Усталость», «Нелинейное» и «Линейная динамика») можно выполнять комбинированный анализ резонансных частот и формы колебаний, линейных продольных нагрузок и форм колебаний, срока службы и повреждений от циклической нагрузки, линейных реакций на динамическую нагрузку двутавровой балки, который максимально будет приближен к реальным условиям эксплуатации конструкции.

\section{References:}

1. (2016) I-beam.

Available: https://en.wikipedia.org/wiki/I-beam (Accessed: 10.11.2016).

2. (2016) Raschet dvutavra na progib i izgib. Available: http://svoydomtoday.ru/buildingonlayn-calculators/293-raschet-dvutavra-naprogib-i-izgib.html (Accessed: 10.11.2016).

3. Holodnyak YuS, Perig AV, Matveev IA (2012) I-bar strength computation methodology perfection for teaching of engineering disciplines. Bulletin PNRPU. Mechanical engineering, materials science, № 4 (14). - pp. $77-90$.

4. GOST 8239-89. Hot-rolled steel flange beams. Assortment.
5. GOST 380-2005. Common quality carbon steel. Grades.

6. (2016) Analiticheskie reshayushchie programmy. Available: http://help.solidworks.com/2014/RUSSIAN/Sol idWorks/cworks/c_Analysis_Solvers.htm (Accessed: 10.11.2016).

7. (2016) Sozdanie KE setki v SW Simulation. Available:

http://andrewabramov.ru/index.php/ru/blogru/item/44-sozdanie-ke-setki-v-solidworks (Accessed: 10.11.2016).

8. (2016) Factor of safety. Available: https://en.wikipedia.org/wiki/Factor_of_safety (Accessed: 10.11.2016). 